30(5), 633-645

\title{
A statistical procedure of analyzing container ship operation data for finding fuel consumption patterns
}

\author{
Kyung-Jun Kim ${ }^{a} \cdot$ Su-Dong Lee ${ }^{a} \cdot$ Chi-Hyuck Jun ${ }^{a, 1} \cdot$ Kae-Myoung Park $^{b}$. \\ Sang-Su Byeon ${ }^{c}$ \\ ${ }^{a}$ Department of Industrial and Management Engineering, Pohang University of Science and \\ Technology; ${ }^{b}$ Korean Register of Shipping; ${ }^{c}$ Hyundai Ocean Service CO., LTD
}

(Received July 05, 2017; Revised September 02, 2017; Accepted October 08, 2017)

\begin{abstract}
This study proposes a statistical procedure for analyzing container ship operation data that can help determine fuel consumption patterns. We first investigate the features that affect fuel consumption and develop the prediction model to find current fuel consumption. The ship data can be divided into two-type data. One set of operation data includes sea route, voyage information, longitudinal water speed, longitudinal ground speed, and wind, the other includes machinery data such as engine power, rpm, fuel consumption, temperature, and pressure. In this study, we separate the effects of external force on ships according to Beaufort Scale and apply a partial least squares regression to develop a prediction model.
\end{abstract}

Keywords: ship operation efficiency, Beaufort Scale, PLS regression

\section{1. 서론}

선박의 배기가스 관련 국제환경규제의 강화로 인해, 선박 운항의 에너지효율 제고의 필요성이 대두되고 있는 상황이다. 실제로, 국제해사기구(International Maritime Organization; IMO)는 2016년 이후 선 박 배출 통제지역(emission control area; ECA)에서 기존배출 규제의 $80 \%$ 의 질소산화물 감축을 목표 로 하는 규제를 채택하였고, $\mathrm{EU}$ 는 대규모 산.학.연 공동프로젝트 등을 통해 친환경 선박 기술 개발 및 환경규제에 범국가적으로 공동대응 중이다. 또한, 일본 조선 업계의 경우 2014년 4월 공동 연구 플랫폼 으로서 기술 연구개발을 전문으로 하는 Maritime Innovation Japan Corporation (MIJAC)를 설립하 고, 이를 통해 조선업계 기업, 선박 기자재 기업, 일본해사협회, 일본정책 투자은행 등이 참여하여 조선, 해운, 해양 등과 관련하여 에너지 효율 제고, 친환경 조선, 해양 기술 개발 등의 연구를 수행하고 있다. 국제환경규제 강화뿐만 아니라, 국제경기 침체의 장기화로 인한 해운업계의 불황을 타개하기 위해 연료 및 유지보수 비용 절감 등을 통한 다각적인 경쟁력 향상의 방안이 필요하다.

This research was a part of the project titled 'Development of TCS system on ECO-Ship technology', funded by the Ministry of Oceans and Fisheries, Korea.

${ }^{1}$ Corresponding author: Department of Industrial and Management Engineering, Pohang University of Science and Technology, 77 Cheongam-ro, Nam-Gu, Pohang, Gyeongbuk 37673, Korea.

E-mail: chjun@postech.ac.kr 
최근에 빅데이터의 수집, 저장 및 처리기술의 발달로 선박의 실시간 운항정보 및 기기상태 모니터링 데 이터 활용을 위한 시스템이 주요 선진국의 해운업계를 시작으로 보급 및 확산되는 추세이다. 본 연구에 서는 특정 선박에서 수집된 운항데이터에 partial least squares (PLS) 회귀분석 (Geladi와 Kowalski, 1986; Jun, 2012)을 적용하여 선박의 연료효율과 관련하여 현재 운항 상태의 적정여부를 판단하고, 환 경요인에 대한 선박의 운항을 탐색하고자 한다.

선박 운항 에너지효율 관리 방법으로 여러 방법이 존재하며, 항해성능관리(voyage performance management), 선체 및 프로펠러 조건관리(hull and propeller condition management), 그리고 선박시스 템관리(ship system management) 측면으로 분류할 수 있다 (American Bureau of Shipping, 2013). 본 연구에서는 항해성능관리를 집중적으로 다루며, 이는 선박 운항 관련 변수(운행 및 환경 변수 등) 를 관리함으로써 에너지효율을 최대화하는 것을 말하며, 항해속도최적화, 최적항로, 트림(trim)/드래프 트(draft) 최적화 등을 포함한다.

선박 운항 에너지효율 표준 개발을 위해서는 선행적으로 에너지효율 관련 변수 선정이 중요하다고 알려 져 있으며, 여러 연구에서 에너지효율 관련 변수를 제시하였다. Armstrong (2013)은 선박의 속도, 선 박, 날씨 등을 언급하였으며, Ballou (2013)은 선박 종류, 화물, 운항 거리 및 시간, 재항시간을 언급하 였고, Moon과 Woo (2014)는 재항시간, 선박 종류, 항해 시간, 선박의 속도, 그리고 Ando (2015)는 선 박의 속도, 바람 속도, 파도 높이, 파랑 주기, 날씨 등을 에너지효율 관련 변수로 제시하였다.

위의 관련 변수들과 에너지효율 간의 관계 분석을 통해 선박 운항 에너지효율 표준을 개발한 다양한 연 구들이 존재한다. Kwon과 $\operatorname{Kim}(2005)$ 는 해상에서의 선속 손실량 산정을 위한 약산식을 제안하였고, 이는 Beaufort Number와 체적 배수량 등을 고려하여 해상의 파도, 바람, 그리고 표면조도 등에 기인된 선속의 손실량을 개발하였다. Armstrong (2013)은 선박 운행 속도와 연료 소모량 간의 관계를 분석하 였고, Ando (2015)는 Armstrong (2013) 보다 한 단계 더 나아가, 바다 상태 별 선박 운행 속도와 연료 소비율 간의 관계를 분석하였다. 또한, Moon과 Woo (2014)는 선박 종류 별 재항시간과 비용 효과 및 이산화탄소 배출량 간의 관계를 회귀분석과 민감도 분석을 활용하여 분석하였다.

본 연구의 구성은 다음과 같다. 2 절에서는 본 연구에서 사용하는 분석 절차 및 각 방법론들에 대해 고찰 하며, 3 절에서는 운항데이터 분석을 통해 선박 운항효율 예측모델에 대한 실험결과를 요약한다. 마지막 으로 4 절의 결론으로 이어진다.

\section{2. 통계적 분석 절차}

본 연구에서 제안하는 운항데이터의 분석 절차는 Figure 2.1 과 같으며, 각 단계에서 진행하는 내용과 방 법론들은 아래와 같다.

선박의 특성상 외력의 영향을 많이 받으며, 외력에 따라 에너지를 소모하는 양이나 비율 또한 크게 달라 지게 된다. 이에 Step 1에서는 외력에 대한 영향을 운항 중에 발생하는 바람의 속도를 통해 얻으며, 이 를 보퍼트 풍력계급(Beaufort Scale; BFS)을 통해 표현한다. BFS는 바람의 속도를 기준으로 BFS0부 터 BFS12까지 총 13 단계로 나눈 계급을 말하며, 이는 실해역에서 선박의 운항성능 분석/평가를 하거나 항로를 설정할 때 매우 중요한 정보이다. BFS에 대한 정보는 Table 2.1과 같다.

선박의 운항데이터에 속하는 각 변수들은 선박의 에너지 소모와 선형 관계가 아닌 특정 비선형 함수 로 표현될 수 있는 물리적인 관계를 갖는다. 이를 반영하기 위해 Figure 2.1의 Step 2에서와 같이 Curve Fitting을 통해 종속변수에 대한 독립변수의 파생변수를 생성하는 과정을 거친다. Curve Fitting을 통해 얻은 독립변수의 파생변수를 사용함으로써, 종속변수와의 선형관계를 증가시켜 개선된 예 측모형을 얻을 수 있다. 독립변수의 파생변수에 대한 예시로, 독립변수 $x=[1,2,3]^{T}$, 종속변수 $y=$ 


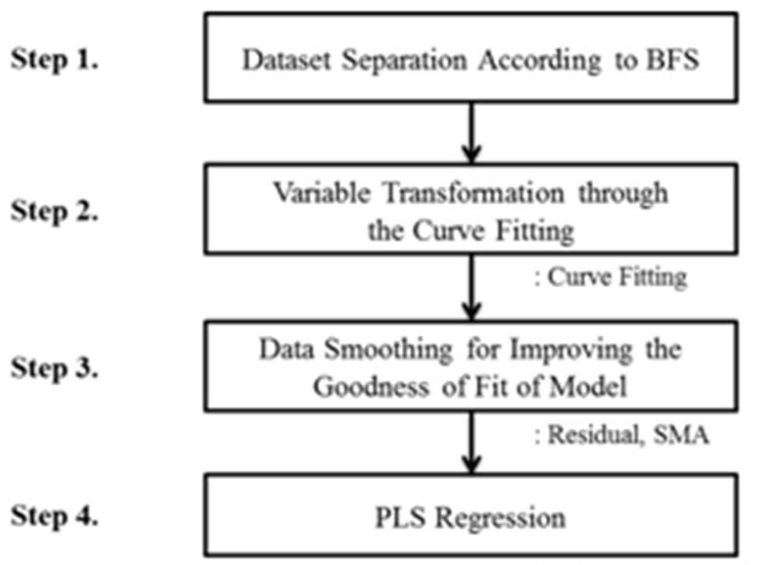

: PLS Regression, VIP

Figure 2.1. Statistical analysis procedure. $B F S=$ Beaufort Scale; SMA $=$ simple moving average; PLS $=$ partial least squares; VIP = variable importance in projection.

Table 2.1. Information of the Beaufort Scale (BFS)

\begin{tabular}{lrrl}
\hline \multirow{2}{*}{ BFS } & \multicolumn{2}{c}{ Wind speed $(\mathrm{m} / \mathrm{s})$} & \\
\cline { 2 - 3 } & Over & Under & Strength \\
\hline BFS0 & 0.0 & 0.3 & Calm \\
BFS1 & 0.3 & 1.6 & Light Air \\
BFS2 & 1.6 & 3.4 & Light Breeze \\
BFS3 & 3.4 & 5.5 & Gentle Breeze \\
BFS4 & 5.5 & 8.0 & Moderate Breeze \\
BFS5 & 8.0 & 10.8 & Fresh Breeze \\
BFS6 & 10.8 & 13.9 & Strong Breeze \\
BFS7 & 13.9 & 17.2 & Near Gale \\
BFS8 & 17.2 & 20.8 & Gale \\
BFS9 & 20.8 & 24.5 & Strong Gale \\
BFS10 & 24.5 & 28.5 & Storm \\
BFS11 & 28.5 & 32.7 & Violent Storm \\
BFS12 & 32.7 & & Hurricane \\
\hline
\end{tabular}

$[2.4630,18.1994,134.4763]^{T}$ 가 주어졌을 때 이 둘의 상관계수는 0.9154 이다. 하지만 여기서 독립변수 와 종속변수는 $y=f(x)=(1 / 3) \exp (2 * x)$ 라는 비선형 관계를 갖고 있으며, 해당 $f(x)$ 에서 상수를 제 외한 $\exp (2 * x)$ 를 통해 종속변수와 선형 관계인 파생변수를 생성하게 되면 1.0000 의 상관계수를 갖게 된다. 즉 파생변수 $x_{\text {new }}=\exp (2 * x)$ 를 기존의 독립변수와 대체함으로써 예측모형의 성능을 향상시킬 수 있다.

운항데이터의 경우, 외력에 의해 순간적으로 관측치가 비정상적으로 측정될 수 있는 동시에 선박의 운 항 특성상 그 변동이 매우 심하기 때문에, Step 3에서는 모형의 $R^{2}$ 향상을 위한 데이터 평활화(data smoothing)을 진행한다. 이를 위해, 회귀모형의 잔차(residual)와 단순이동평균(simple moving average; SMA)을 적용한다.

종속변수의 실제 값 $y$ 와 예측 값 $\hat{y}$ 의 차이인 회귀모형 잔차 $r(=y-\hat{y})$ 에 대한 정규분포 가정을 통해 신 


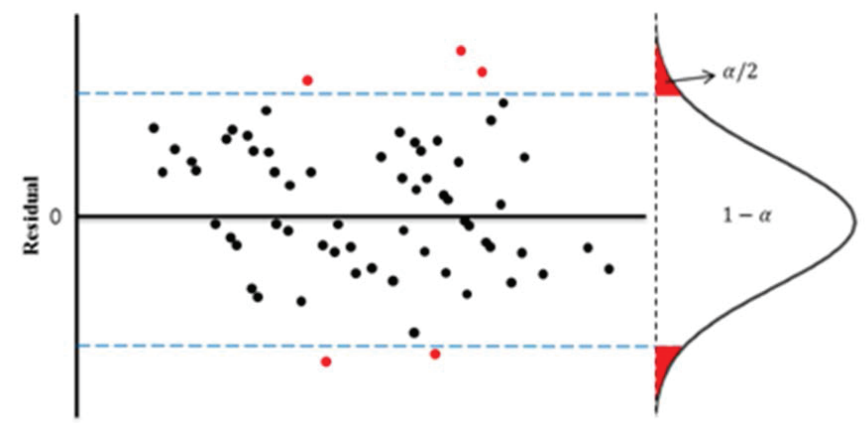

Figure 2.2. Example of outlier elimination.

뢰수준(significance level)을 나타내는 값인 특정 $\alpha$ 를 설정하여, Figure 2.2 와 같이 그 정도를 벗어나는 관측치들을 이상치(outlier)로 간주하고 제거한다. 이를 통해 예측모형의 $R^{2}$ 를 향상시킨다.

운항데이터의 관측치는 선박에서 10 분마다 측정되는 시계열 데이터인 동시에 외력에 의해 측정되는 관 측치의 값의 변동 폭이 굉장히 넓은 데이터이다. 이러한 불규칙한 변동을 완화하기 위해, Figure 2.1의 Step 3에서 이상치를 제거하는 것과 더불어 SMA를 적용하며, 이에 따른 수식은 아래와 같다.

$$
\mathrm{SMA}_{t-(T-1)}=\frac{(x, y)_{t}+(x, y)_{t-1}+\cdots+(x, y)_{t-(T-1)}}{T},
$$

여기서 $x_{i} \in \mathbb{R}^{k}$ 는 $k$ 개의 독립변수로 이루어진 $i$ 번째 관측치, $y \in \mathbb{R}$ 는 종속변수, $t$ 는 현재의 기준 시점을 나타내며, $T$ 는 이동평균을 낼 타임윈도우(time window)를 의미한다. 이에 따라 최종적으로 $t-(T-1)$ 개의 SMA가 적용된 새로운 데이터들을 얻게 된다. 타임윈도우의 경우 너무 낮은(높은) 값 으로 설정을 하게 되면, 원래 데이터의 불규칙한 변동이 완화되지 않는(원래 데이터의 성질을 잃어버리 는) 문제가 발생할 수 있어, 적절한 값을 설정하는 것이 중요하다.

분석 절차 중에서 마지막인 Step 4에서는 PLS 회귀분석을 통해 선박의 운항효율 예측모델을 수립한다. 이는 독립변수들 간의 중복성을 고려하여 종속변수를 가장 잘 설명하는 최적의 잠재변수들을 찾음과 동 시에 중요한 영향을 미치는 독립변수들을 variable importance in projection (VIP)를 통해 선택하기 위함이다. PLS 회귀분석의 모형에 대한 수식은 아래와 같다.

$n$ 개의 관측치와 $k$ 개의 독립변수가 주어졌을 때, $n \times k$ 데이터행렬 $\boldsymbol{X}$, 종속변수벡터 $\boldsymbol{y}$ 에 대하여 동시에 $A$ 개의 잠재변수 $t_{a}(a=1, \ldots, A)$ 로 설명할 수 있는 모형을 고려할 수 있으며, 그 관계식은 아래와 같 다. 즉, $A$ 는 잠재변수 수로서 독립변수 수 $k$ 보다 적다.

$$
\begin{aligned}
\boldsymbol{X} & =\boldsymbol{t}_{1} \boldsymbol{p}_{1}^{T}+\boldsymbol{t}_{2} \boldsymbol{p}_{2}^{T}+\cdots+\boldsymbol{t}_{A} \boldsymbol{p}_{A}^{T}+\boldsymbol{E}, \\
\boldsymbol{y} & =\boldsymbol{t}_{1} b_{1}+\boldsymbol{t}_{2} b_{2}+\cdots+\boldsymbol{t}_{A} b_{A}+\boldsymbol{f} .
\end{aligned}
$$

여기서 $\boldsymbol{p}_{a}$ 는 $\boldsymbol{X}$ 에 대응하는 로딩(loading)을 나타내며, $\boldsymbol{E}$ 와 $\boldsymbol{f}$ 는 각 모델에 해당하는 오차항이다. 이에 대한 계수 및 잠재변수 값들을 아래와 같은 단계를 통하여 산출할 수 있고, $A$ 개의 잠재변수를 구할 때까 지 반복한다.

단계 1. $\boldsymbol{X}$ 의 각 열벡터를 종속변수로 $\boldsymbol{y}$ 를 독립변수로 하는 단순회귀모형으로부터 $\boldsymbol{y}$ 의 기울기를 추정하 여 가중치 $\boldsymbol{w}=\left(w_{1}, \ldots, w_{k}\right)^{T}$ 를 산출하고 이의 크기가 1 이 되도록 조정한다.

$$
w_{j}=\frac{\boldsymbol{x}_{j}^{T} \boldsymbol{y}}{\boldsymbol{y}^{T} \boldsymbol{y}}, \quad j=1, \ldots, k ; \boldsymbol{w} \leftarrow \frac{\boldsymbol{w}}{\sqrt{\boldsymbol{w}^{T} \boldsymbol{w}}} .
$$


단계 2. $\boldsymbol{t}$ 를 다음과 같이 산출한다.

$$
\boldsymbol{t}=w_{1} \boldsymbol{x}_{1}+\cdots+w_{k} \boldsymbol{x}_{k}=\boldsymbol{X} \boldsymbol{w} .
$$

단계 3. $\boldsymbol{t}$ 를 $\boldsymbol{X}$ 에 회귀시켜 로딩 벡터 $\boldsymbol{p}$ 를 다음과 같이 구한다.

$$
\boldsymbol{p}=\frac{X^{T} \boldsymbol{t}}{\boldsymbol{t}^{T} \boldsymbol{t}}
$$

단계 4. 로딩 벡터 $\boldsymbol{p}$ 의 크기를 반영하여 $\boldsymbol{t}$ 와 $\boldsymbol{w}$ 를 조정한 뒤 $\boldsymbol{p}$ 의 크기를 1 이 되도록 조정한다.

$$
t \leftarrow t \sqrt{p^{T} p}, \quad w \leftarrow w \sqrt{p^{T} p}, \quad p \leftarrow \frac{p}{\sqrt{p^{T} p}} .
$$

단계 5. $\boldsymbol{t}$ 를 $\boldsymbol{y}$ 에 회귀시킬 때, 계수 $b$ 를 산출한다.

$$
b=\frac{\boldsymbol{y}^{T} \boldsymbol{t}}{\boldsymbol{t}^{T} \boldsymbol{t}}
$$

단계 6. $\boldsymbol{X}$ 와 $\boldsymbol{y}$ 를 다음과 같이 수정 후, $A$ 개의 잠재변수를 얻을 때까지 단계 1 부터 과정을 반복한다.

$$
\boldsymbol{X} \leftarrow \boldsymbol{X}-\boldsymbol{t p}^{T} \quad\left(\boldsymbol{x}_{j} \leftarrow \boldsymbol{x}_{j}-p_{j} \boldsymbol{t}, j=1, \ldots, k\right), \quad \boldsymbol{y} \leftarrow \boldsymbol{y}-b \boldsymbol{t} .
$$

이렇게 얻은 새로운 잠재변수들을 통해, 종속변수 $y$ 에 대한 예측식의 형태는 기존의 다중선형회귀분석 과 유사하다.

$$
\hat{\boldsymbol{y}}=\hat{b}_{1} \boldsymbol{t}_{1}+\cdots+\hat{b}_{A} \boldsymbol{t}_{A}=\boldsymbol{T} \hat{\boldsymbol{b}} .
$$

$\mathrm{VIP}$ 는 원래의 각 독립변수가 실질적으로 종속변수에 얼마나 영향을 미치는 지를 나타내는 독립변수의 중요도 척도이며, 이는 PLS에서 각 독립변수가 잠재변수에 얼만큼 영향을 주며 다시 이러한 잠재변수 들이 종속변수에 어떤 영향을 미치는 지를 동시에 고려한 값이다. $j$ 번째 독립변수에 대한 VIP는 아래 와 같이 정의한다.

$$
\operatorname{VIP}_{j}=\sqrt{\frac{k}{\operatorname{SSR}} \sum_{a=1}^{A} \operatorname{SSR}_{a}\left(\frac{w_{a j}}{\left\|\boldsymbol{w}_{a}\right\|}\right)^{2}}, \quad j=1, \ldots, k
$$

이며, $w_{a j}$ 는 독립변수 $\boldsymbol{f}_{j}$ 의 잠재변수 $\boldsymbol{t}_{a}$ 에 대한 기여도, $\mathrm{SSR}_{a}$ 는 $a$ 번째 잠재변수가 종속변수 $\boldsymbol{y}$ 를 설명 하는 기여도로서 회귀제곱 합으로 구할 수 있다. || $\boldsymbol{w}_{a}||$ 는 $\sum_{j} w_{a j}^{2}$ 의 값이 1 이 되도록 하는 정규화 값이 다.

위의 정의에 따르면, 아래와 같은 성질이 성립하므로,

$$
\sum_{j=1}^{k} \mathrm{VIP}_{j}^{2}=k
$$

독립변수들의 VIP 제곱의 평균은 1 임을 알 수 있다. 따라서, VIP가 1 보다 큰 독립변수를 유의한 독립 변수로 간주하는 것이 일반적이다.

지금까지의 분석을 이용하여 선박의 운항을 탐색 하기 위해, BFS 별로 PLS 회귀분석의 VIP를 통해 얻 어진 중요독립변수들에 대해 외력의 차이를 데이터 상에서 확인할 수 있는 지에 대한 분석을 시각화를 통해 진행한다. 
Table 3.1. Information of independent variables and target

\begin{tabular}{|c|c|c|c|}
\hline Type & Name & Description & Unit \\
\hline \multirow{10}{*}{$\begin{array}{c}\text { Independent } \\
\text { variable }\end{array}$} & LWS & Longitudinal water speed & knots \\
\hline & LGS & Longitudinal ground speed & knots \\
\hline & POWER & Engine power & $\mathrm{kW}$ \\
\hline & $\mathrm{RPM}$ & Revolutions per minute & $\mathrm{rpm}$ \\
\hline & Trim & Slope of the ship & $m$ \\
\hline & Draft & Depth of the ship under water & $m$ \\
\hline & Displacement & Displacement & $t$ \\
\hline & Wetted surface & Wetted surface of the ship & $m^{2}$ \\
\hline & Propeller immersion & Propeller immersion & $\%$ \\
\hline & Wind resistance & Wind resistance & $\mathrm{kN}$ \\
\hline \multirow{2}{*}{ Target } & SFOC & Specific fuel oil consumption & $\mathrm{g} / \mathrm{kWh}$ \\
\hline & FOC & Fuel oil consumption & $\mathrm{l} / \mathrm{h}, \mathrm{kg} / \mathrm{h}$ \\
\hline
\end{tabular}

Table 3.2. Component ratio of the data according to Beaufort Scale (BFS) and direction

\begin{tabular}{ccc|crr}
\hline East-Bound & Observation & Ratio $(\%)$ & West-Bound & Observation & Ratio (\%) \\
\hline BFS0 & 391 & 0.92 & BFS0 & 186 & 0.44 \\
BFS1 & 972 & 2.29 & BFS1 & 617 & 1.45 \\
BFS2 & 2,619 & 6.16 & BFS2 & 1,912 & 4.50 \\
BFS3 & 5,011 & 11.78 & BFS3 & 3,862 & 9.09 \\
BFS4 & 7,680 & 18.06 & BFS4 & 6,062 & 14.26 \\
BFS5 & 7,208 & 16.95 & BFS5 & 6,996 & 16.46 \\
BFS6 & 6,777 & 15.94 & BFS6 & 8,328 & 19.60 \\
BFS7 & 5,095 & 11.98 & BFS7 & 6,881 & 16.19 \\
BFS8 & 3,304 & 7.77 & BFS8 & 5,732 & 13.49 \\
BFS9 & 2,477 & 5.83 & BFS9 & 1,693 & 3.98 \\
BFS10 & 795 & 1.87 & BFS10 & 225 & 0.53 \\
BFS11 & 188 & 0.44 & BFS11 & 3 & 0.01 \\
BFS12 & 4 & 0.01 & BFS12 & Total & 0.00 \\
\hline Total & 42,521 & 100.00 & & 42,497 & 100.00 \\
\hline
\end{tabular}

\section{3. 운항데이터 분석 결과}

이 장에서는 운항데이터 분석을 통해 선박 운항효율 예측모델과 선박의 운항의 탐색에 대한 실험결과를 요약한다.

\section{1. 데이터}

본 연구에서 사용된 운항데이터는 2014년 2월부터 2016년 7 월까지 약 2 년 6 개월 동안 $6,800 \mathrm{TEU}$ 컨테 이너선에서 얻어진 것으로, 독립변수의 총 개수는 917 개이며 관측치는 10 분마다 측정되는 시계열 데이 터이다. 이 중에서 Sea-Going 항해 구간에 대한 데이터를 이용하였으며, 선박은 항해할 때 환경조건에 따라 성능이 다르게 나타나며, 동쪽으로 갈 때의 조류, 기상조건이 서쪽으로 갈 때와는 사뭇 다르기 때 문에 항해 방향에 따라 동쪽으로 항해하는 East-Bound와 서쪽으로 항해하는 West-Bound로 구분하였 다. 이론적 이상치를 제거한 운항데이터의 관측치 수는 East-Bound에서는 42,521 개, West-Bound에 서는 42,497 개로 이루어져 있다.

본 연구에서는 변수선택법(feature selection)을 적용하지 않고, Table 3.1 과 같이 전문가들의 의견을 반 
Table 3.3. Results of curve fitting

\begin{tabular}{|c|c|c|c|c|c|c|c|c|c|c|c|}
\hline \multirow[b]{2}{*}{ Target } & & \multicolumn{10}{|c|}{ Independent variable } \\
\hline & & LWS & LGS & RPM & Draft & $\begin{array}{l}\text { Displace- } \\
\text { ment }\end{array}$ & $\begin{array}{l}\text { Wetted } \\
\text { surface }\end{array}$ & Trim & $\begin{array}{c}\text { Wind } \\
\text { resistance }\end{array}$ & POWER & $\begin{array}{l}\text { Propeller } \\
\text { immersion }\end{array}$ \\
\hline SFOC & & $\mathrm{P}$ & $\mathrm{P}$ & $\mathrm{P}$ & $\mathrm{L}$ & $\mathrm{L}$ & $\mathrm{L}$ & $\mathrm{L}$ & $\mathrm{L}$ & $\mathrm{P}$ & $\mathrm{L}$ \\
\hline \multirow{3}{*}{$R$-squared } & $\mathrm{L}$ & 0.2618 & 0.2427 & 0.2766 & - & - & - & - & - & 0.3054 & - \\
\hline & $\mathrm{E}$ & 0.3153 & 0.3152 & 0.3272 & - & - & - & - & - & 0.4811 & - \\
\hline & $\mathrm{P}$ & 0.3326 & 0.3388 & 0.3496 & - & - & - & - & - & 0.4946 & - \\
\hline$b$ & & -0.88 & -0.69 & -1.54 & - & - & - & - & - & -0.62 & - \\
\hline $\mathrm{FOC}$ & & $E$ & $\mathrm{E}$ & $E$ & $\mathrm{~L}$ & $\mathrm{~L}$ & $\mathrm{~L}$ & $\mathrm{~L}$ & $\mathrm{~L}$ & $\mathrm{~L}$ & $\mathrm{~L}$ \\
\hline \multirow{3}{*}{$R$-squared } & $\mathrm{L}$ & 0.4293 & 0.4154 & 0.5368 & - & - & - & - & - & - & - \\
\hline & $\mathrm{E}$ & 0.5959 & 0.5636 & 0.6186 & - & - & - & - & - & - & - \\
\hline & $\mathrm{P}$ & 0.5887 & 0.5585 & 0.6026 & - & - & - & - & - & - & - \\
\hline$b$ & & 0.12 & 0.12 & 0.03 & - & - & - & - & - & - & - \\
\hline
\end{tabular}

$\mathrm{L}=$ linear; $\mathrm{E}=$ exponential; $\mathrm{P}=$ power.

Table 3.1 provides descriptions on the abbreviated names of independent variable and target.

영한 10 개의 독립변수와 2 개의 종속변수를 활용해 분석을 진행한다. 2 개의 종속변수는 각각 specific fuel oil consumption (SFOC)와 fuel oil consumption (FOC)로 서로 독립적이지 않으며, SFOC의 단 위는 $\mathrm{g} /(\mathrm{kW} \times \mathrm{hour})$ 로 단위일당 연료소모량을, $\mathrm{FOC}$ 의 단위는 liter/hour로 연료소모량을 나타낸다.

\section{2. 환경요인을 고려한 운항데이터 구분}

외력에 의해 데이터가 받는 영향을 파악하기 위해 $\mathrm{BFS}$ 를 기준으로 운항데이터를 구분하였고, 그 결과 는 Table 3.2 와 같다.

\subsection{Curve Fitting을 통한 파생변수 생성}

선택된 10 개의 독립변수와 종속변수 간의 일대일 함수 관계를 확인하며, 변수 간 관계함수로는 아래와 같이 linear, exponential, 그리고 power 함수를 사용한다.

$$
\begin{aligned}
\text { linear: } f(x) & =a \times x+b, \\
\text { exponential: } f(x) & =a \times \exp (b \times x), \\
\text { power: } f(x) & =a \times x^{b} .
\end{aligned}
$$

각 독립변수와 종속변수에 대해, 가장 높은 $R$-squared 값을 갖는 함수를 최종 함수로 선택한다. 이에 대한 결과는 Table 3.3 과 같다.

\section{4. 모형의 $R^{2}$ 향상을 위한 데이터 필터링}

운항데이터의 경우, 외력에 의해 순간적으로 관측치가 비정상적으로 측정될 수 있기 때문에, 이를 방지 하지 위해 회귀모형의 잔차와 $\mathrm{SMA}$ 를 적용한다. 이에 앞서 모든 독립변수는 curve fitting을 통해 얻어 진 선형화된 파생변수를 사용한다.

회귀모형 잔차의 경우, 회귀모형으로부터 실제 종속변수의 값과 회귀모형에 의해 추정된 값의 차이인 잔 차를 계산하여, 이 값이 신뢰구간을 벗어나는 관측치를 이상치(outlier)로 간주하고 제거하여 예측모형 의 $R^{2}$ 를 향상시킨다. 여기서, 유의수준은 $\alpha=0.5$ 로 설정한다. 
Table 3.4. VIP through the PLS regression

\begin{tabular}{ccccccccccc}
\hline & LWS & LGS & RPM & Draft & $\begin{array}{c}\text { Displace- } \\
\text { ment }\end{array}$ & $\begin{array}{c}\text { Wetted } \\
\text { surface }\end{array}$ & Trim & $\begin{array}{c}\text { Wind } \\
\text { resistance }\end{array}$ & POWER & $\begin{array}{c}\text { Propeller } \\
\text { immersion }\end{array}$ \\
\hline East-Bound & $\mathbf{1 . 3 8}$ & $\mathbf{1 . 2 9}$ & $\mathbf{1 . 5 2}$ & 0.38 & 0.39 & 0.39 & 0.48 & 0.55 & $\mathbf{1 . 6 0}$ & 0.37 \\
West-Bound & $\mathbf{1 . 4 7}$ & $\mathbf{1 . 4 0}$ & $\mathbf{1 . 5 0}$ & 0.47 & 0.47 & 0.47 & 0.25 & 0.50 & $\mathbf{1 . 5 3}$ & 0.41 \\
\hline
\end{tabular}

VIP $=$ variable importance in projection; PLS $=$ partial least squares.

Table 3.1 provides descriptions on the abbreviated names of independent variable.
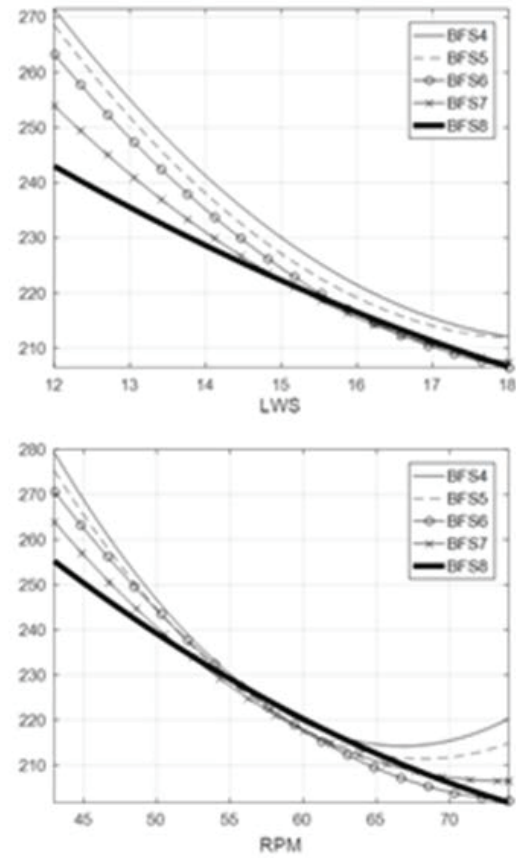
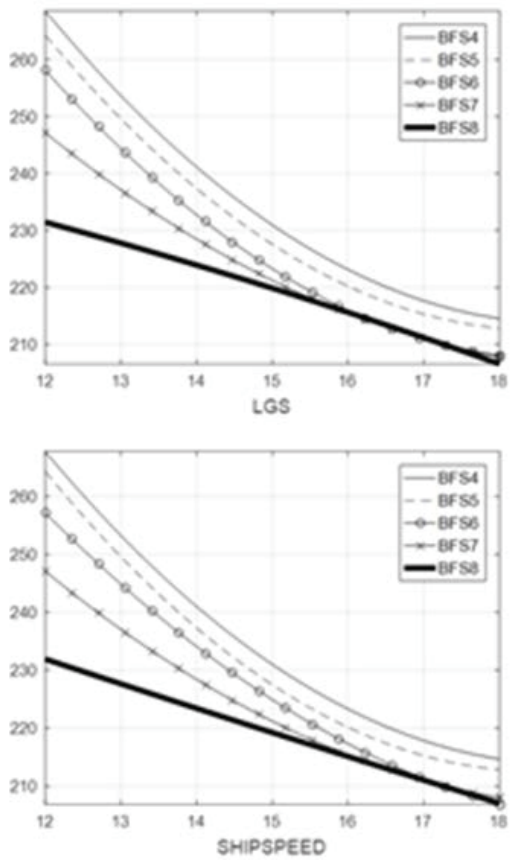

Figure 3.1. Results of the fitting with (East-Bound \& SFOC). BFS = Beaufort Scale; SFOC = specific fuel oil consumption; LWS = longitudinal water speed; LGS = longitudinal ground speed; RPM = revolutions per minute.

$\mathrm{SMA}$ 에서 정해주어야 할 값인 타임윈도우는 $T=24$ 로 설정하며, 이는 관측치를 1 시간 단위(즉, $T=$ $6,12,18,24,30, \ldots)$ 로 증가시키다가 Table 3.3 에서 구한 추정된 값인 $b$ 를 변화시키지 않는 최대값이다.

\section{5. 실험 결과}

운항데이터를 BFS 별로 나누었을 때, 가장 많이 운항을 하고 관심이 있는 구간인 BFS 4-8 구간을 분 석하였고, PLS 회귀분석을 통해 산출된 VIP 값의 평균값에 대한 결과는 Table 3.4 와 같다. VIP를 통 해 얻은 주요변수로 선택된 독립변수들을 이용해 $\mathrm{BFS}$ 별로 종속변수 $\mathrm{SFOC}, \mathrm{FOC}$ 와의 관계가 구분 되어 나타나는지를 파악하게 위해 그 관계를 추정하였고, 주요독립변수는 Table 3.4 와 같이 선박의 속 도를 나타내는 변수들인 LWS, LGS, RPM가 전반적으로 종속변수에 가장 많은 영향을 미치는 변수들 로 선택되었다. 추가적으로 배의 속도인 SHIPSPEED를 사용하였고, 이에 대해 추정된 결과는 Figure $3.1-3.4$ 와 같다.

주요독립변수와 종속변수와의 관계를 추정한 결과, 연료소모량을 나타내는 $\mathrm{FOC}$ 의 경우에는 주요독립 

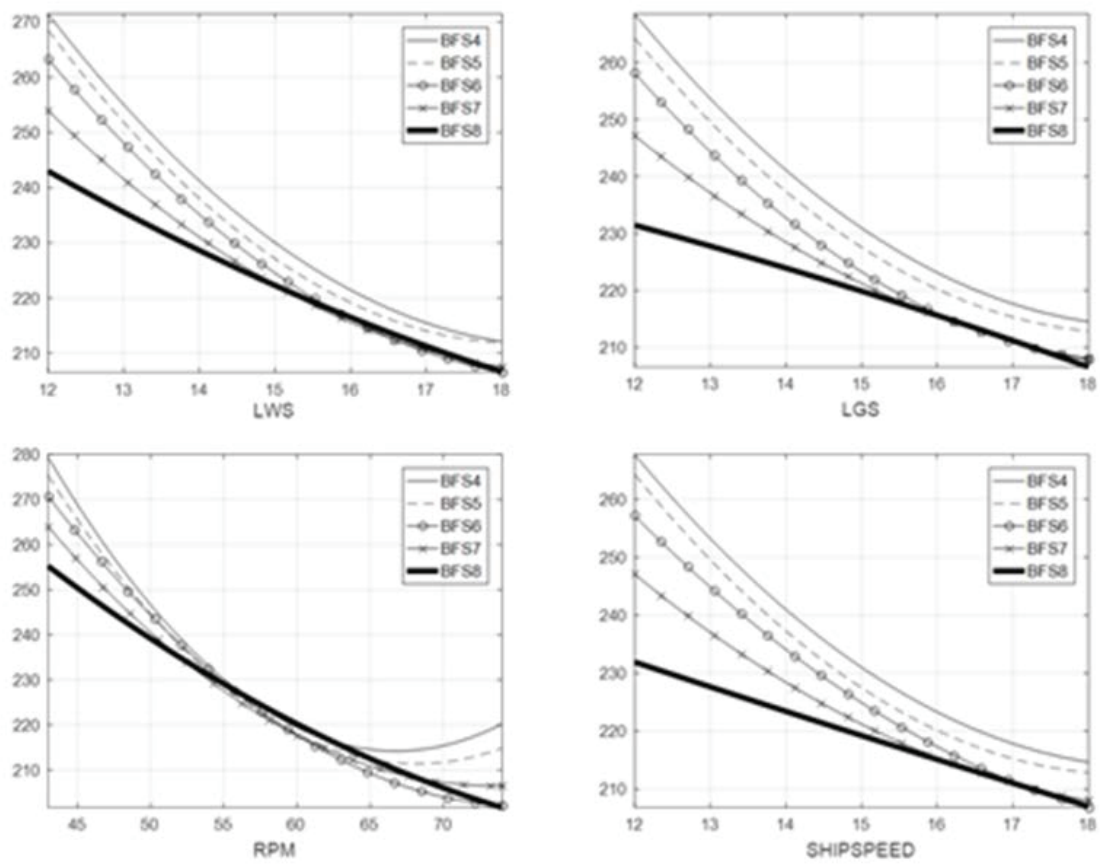

Figure 3.2. Results of the fitting with (West-Bound \& SFOC). BFS $=$ Beaufort Scale; $\mathrm{SFOC}=$ specific fuel oil consumption; LWS $=$ longitudinal water speed; LGS $=$ longitudinal ground speed; RPM $=$ revolutions per minute.
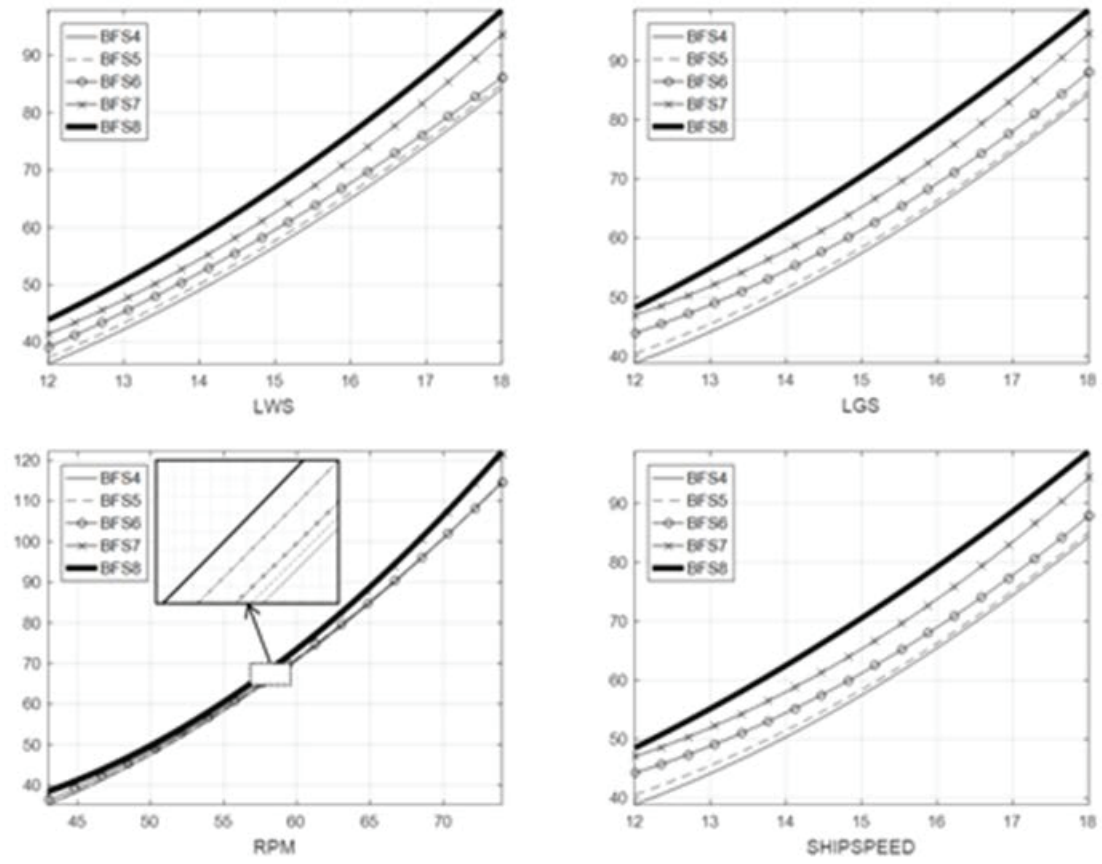

Figure 3.3. Results of the fitting with (East-Bound \& FOC). BFS $=$ Beaufort Scale; SFOC $=$ specific fuel oil consumption; LWS = longitudinal water speed; LGS = longitudinal ground speed; RPM $=$ revolutions per minute. 

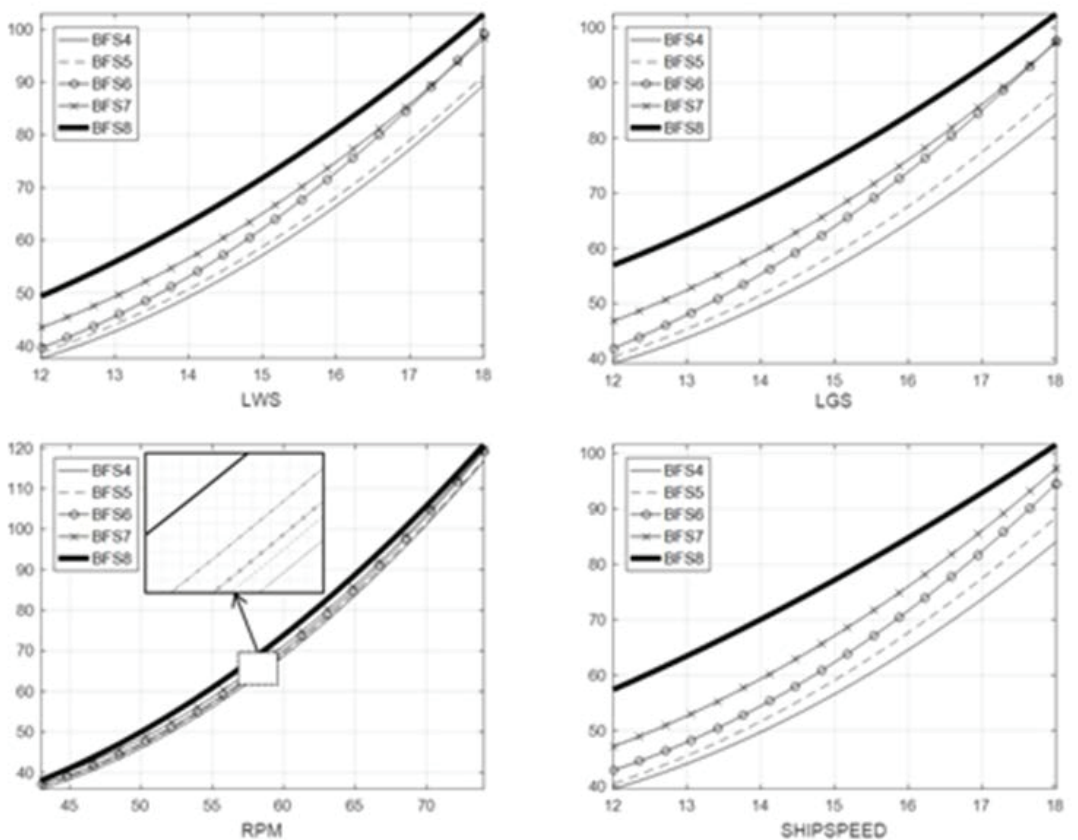

Figure 3.4. Results of the fitting with (West-Bound \& FOC). BFS = Beaufort Scale; SFOC = specific fuel oil consumption; LWS = longitudinal water speed; LGS = longitudinal ground speed; RPM = revolutions per minute.

Table 3.5. Results of the PLS regression with SFOC

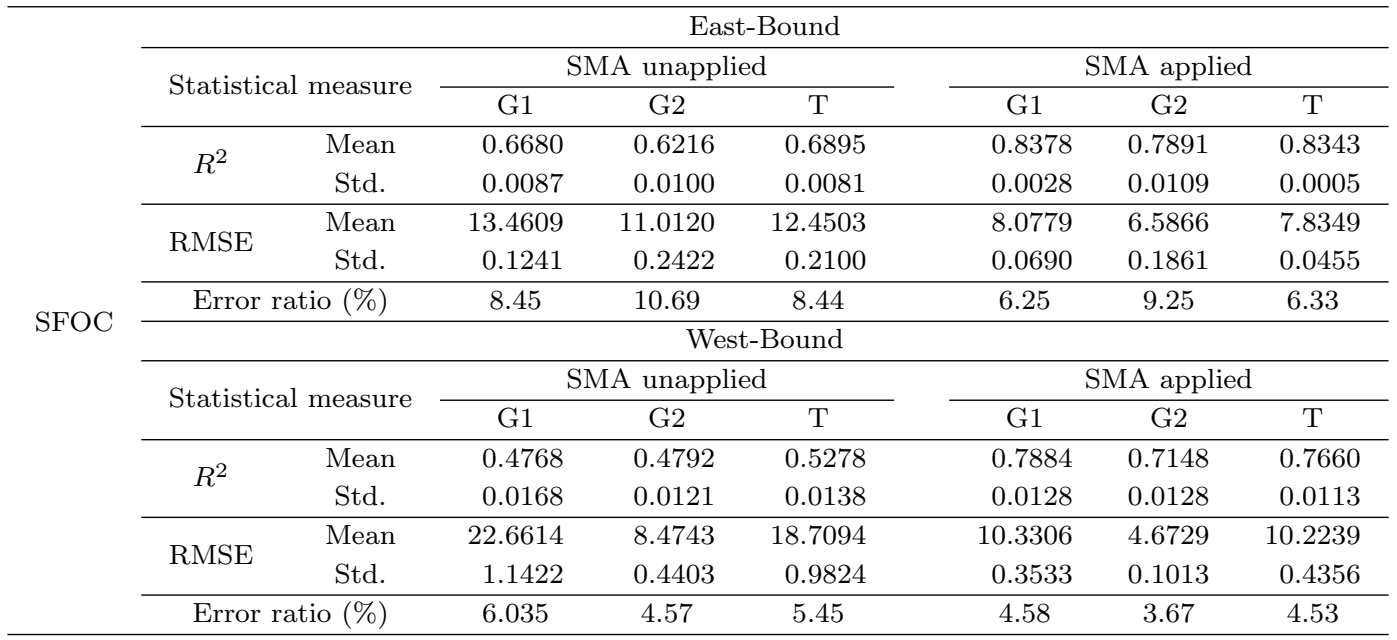

PLS $=$ partial least squares; SFOC $=$ specific fuel oil consumption; SMA = simple moving average; BFS $=$ Beaufort Scale; G1 = BFS 4-6; G2 = BFS 7-8; T $=$ BFS 4-8.

변수들이 증가할수록 증가하는 방향으로 움직이는 것을 알 수 있고, 환경요인인 $\mathrm{BFS}$ 별로 운항의 반 응들이 확연히 구분되어 나타나는 것을 확인할 수 있었다. 이에 반해, 단위일당 연료소모량을 나타내는 $\mathrm{SFOC}$ 의 경우에는 주요독립변수가 증가할수록 감소하는 관계를 갖고 있지만, 일부 결과에서 $\mathrm{BFS}$ 별로 
Table 3.6. Results of the PLS regression with FOC

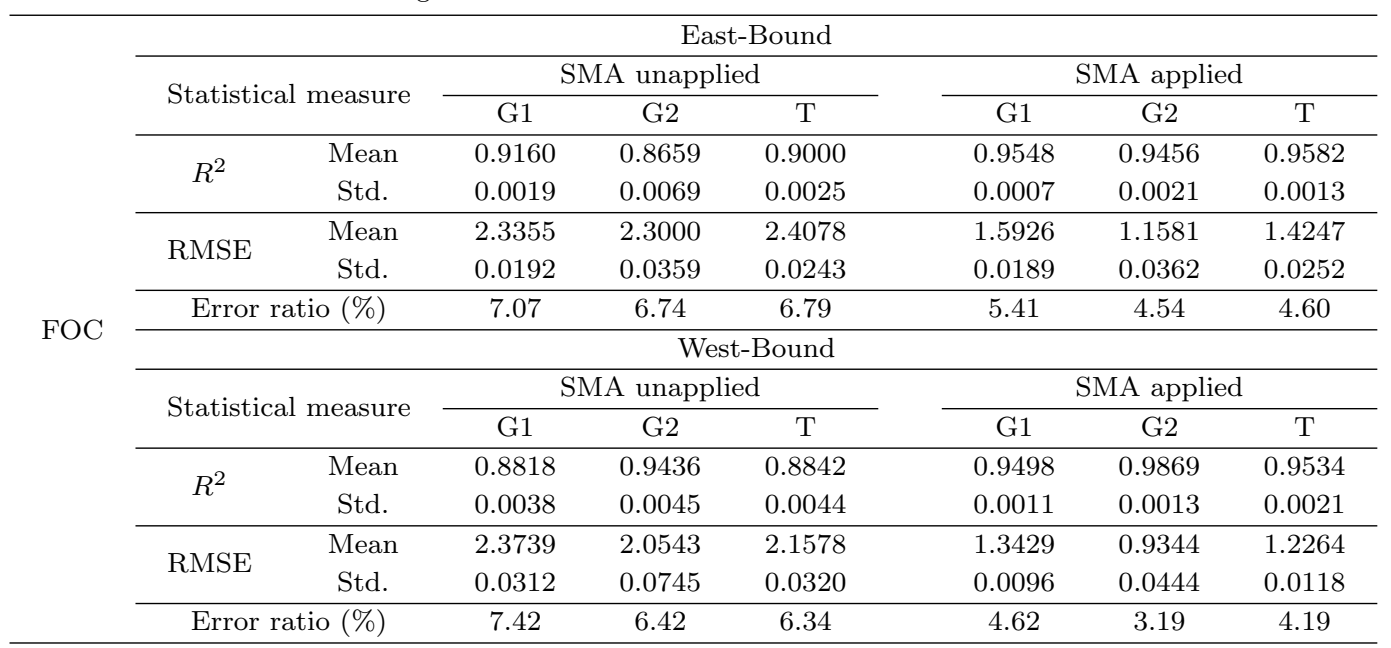

$\mathrm{PLS}=$ partial least squares; FOC = fuel oil consumption; SMA = simple moving average;

$\mathrm{BFS}=$ Beaufort Scale; G1 = BFS 4-6; G2 = BFS 7-8; T = BFS 4-8.

운항의 반응들이 겹치거나 구분이 어려운 구간이 존재하는 것을 확인할 수 있었다.

운항데이터의 회귀분석 또한 BFS 4-8 구간을 분석하였고, 외력을 나타내는 BFS가 비슷한 구간은 그룹 을 지어 결과를 나타내었다. 그룹1은 G1으로 표기하며 BFS 4-6 구간의 데이터들을 함께 사용한다. 마 찬가지로, 그룹2는 G2로 표기하였으며 BFS 7-8 구간의 데이터들을 함께 사용하며, 전체데이터를 나타 내는 표기인 T는 BFS 4-8 모든 구간의 데이터를 함께 사용함을 의미한다.

이러한 운항데이터에 PLS 회귀분석을 적용한 결과는 종속변수 SFOC는 Table 3.5 , 종속변수 FOC는 Table 3.6과 같다. 운항데이터의 회귀분석 결과, 종속변수에 대한 그룹들인 G1, G2, T 간에는 EastBound와 West-Bound 별로도 서로 다른 성능을 보여주었으며, 운항데이터에 SMA를 적용하는 경우, 회귀분석의 성능이 눈에 띄게 향상하는 것을 확인할 수 있었다.

\section{4. 결론}

총 10 개의 독립변수들 중에서, 종속변수인 $\mathrm{SFOC}$ 와 $\mathrm{FOC}$ 에 실질적으로 유의한 영향을 미치는 독립변 수는 LWS, LGS, RPM, POWER와 같이 선박의 속도와 직접적으로 관련이 있는 변수들이었다. 외력 을 나타내는 변수인 Wind Resistance의 경우, 종속변수에 크게 영향을 주는 변수로 보이지는 않지만, 바람의 속도로 $\mathrm{BFS}$ 를 구분해 나타내었기 때문에 외력을 운항데이터에 반영해주었다고 볼 수 있다. 결 과적으로, 종속변수가 $\mathrm{FOC}$ 인 경우에 R-squared와 $\mathrm{RSME}$ 측면에서 가장 좋은 결과를 보이는 것을 알 수 있었고, 종속변수가 $\mathrm{SFOC}$ 인 경우는 산식에 역의 곱으로 POWER가 이용이 되는 동시에 운항데이 터의 특성상 데이터의 관측 범위의 변동이 심하여 $\mathrm{SFOC}$ 의 변동 역시 심화되어, 정확한 예측모델을 수 립하지 못 한 것으로 보인다.

$\mathrm{BFS}$ 별로 독립변수와 종속변와의 관계를 추정한 결과인 Figure 3.1-3.4과도 마찬가지로, 종속변수가 $\mathrm{FOC}$ 인 경우가 $\mathrm{SFOC}$ 인 경우에 비해 $\mathrm{BFS}$ 에 대한 분명한 영향의 차이의 결과를 얻어낼 수 있음을 알 수 있었다. 이를 통해, 선박이 BFS 별로 어느 정도의 에너지를 소모하여야 정상적인 운항을 하고 있는 지를 제시해 줄 수 있다. 또한, BFS에 따른 그룹 별 데이터에서 항해 방향에 따른 East-Bound, West- 
bound와 데이터 평활화를 위한 SMA의 적용에 따른 데이터의 구분도 PLS 회귀분석의 결과를 통해 서 로 다른 성능을 나타내는 것으로 나타나, 상황에 따른 데이터 구분이 분석에서 중요한 요소인 것으로 보 인다.

본 연구에서는 BFS 별로 선박의 운항데이터를 구분지어 분석하였으며, 독립변수와 종속변수 간의 상관 관계를 파악 및 반영한 예측모델을 수립하였다. 기존의 연구에서는 종속변수 $\mathrm{SFOC}, \mathrm{FOC}$ 와 독립변수 LWS, LGS, SHIPSPEED, RPM과의 관계에 대해, RPM의 변화량과 $\mathrm{SFOC}, \mathrm{FOC}$ 의 관계는 공장에서 엔진을 만들 때 나오는 ship test 결과만이 있을 뿐이고 실해역에서 수집된 데이터를 통해 분석된 상관 관계는 없었다. 또한 이 때 해상상태의 등급을 의미하는 BFS 별로 그 상관관계를 산출한 데이터는 전 무하다고 볼 수 있다. 따라서, 분석결과가 산업현장에서는 매우 중요한 실전 테스트 분석결과로 활용될 수 있으며, 구체적으로 BFS 별, 독립변수 별로 실해역에서 선박의 운항성능 분석/평가를 하거나 항로 를 설정하는 데 중요한 내용으로 활용할 수 있다.

향후에는 정성적인 독립변수 선택뿐 만이 아니라 변수선택법을 활용한 정량적인 독립변수 선택을 적용 하고자 한다. 또한 예측모델의 경우, PLS 회귀분석 외에 더 고도화된 다양한 예측모델들을 적용 및 비 교하고자 한다.

\section{References}

American Bureau of Shipping (2013). Ship Energy Efficiency Measures: Status and Guidance, ABS, Houston. Ando, H. (2015). How We Tackle IoT of Ship: Data Utilization and Standardization, International Seminar on Practical Use of Maritime Big Data, MTI, Tokyo.

Armstrong, V. N. (2013). Vessel optimisation for low carbon shipping, Ocean Engineering, 73, 195-207.

Ballou, P. J. (2013). Ship energy efficiency management requires a total solution approach, Marine Technology Society Journal, 47, 83-95.

Björck, Å. (1996). Numerical Methods for Least Squares Problems, SIAM, Philadelphia.

Geladi, P. and Kowalski, B. R. (1986). Partial least-squares regression: a tutorial, Analytica Chimica Acta, 185, 1-17.

Jun, C. H. (2012). Data Mining Techniques and Applications, Hannarae, Seoul.

Kwon Y.-J. and Kim D. Y. (2005). A research on the approximate formulae for the speed loss at sea, Journal of Ocean Engineering and Technology, 19, 90-93.

Moon, D. S. H. and Woo, J. K. (2014). The impact of port operations on efficient ship operation from both economic and environmental perspectives, Maritime Policy \& Management, 41, 444-461. 


\title{
연료 소비 패턴 발견을 위한 컨테이너선 운항데이터 분석의 통계적 절차
}

\author{
김경준 $^{a} \cdot$ 이수동 ${ }^{a} \cdot$ 전치혁 $^{a, 1} \cdot$ 박개명 $^{b} \cdot$ 변상수 $^{c}$ \\ ${ }^{a}$ 포항공과대학교 산업경영공학과, ${ }^{b}\left(\right.$ 사)한국선급, ${ }^{c}$ 현대해양서비스(주)
}

(2017년 07월 05일 접수, 2017년 09월 02일 수정, 2017년 10월 08일 채택)

\section{요 약}

본 연구는 컨테이너선의 연료 소비 패턴의 발견을 위해 운항데이터 분석의 통계적 절차를 제안한다. 우리는 현 시점 의 연료 소비를 발견하기 위해 연료 소비에 영향을 미치는 변수들을 파악하는 동시에 예측 모델을 개발 및 적용하는 것을 목적으로 한다. 선박의 데이터는 크게 운항데이터와 기기데이터로 분류할 수 있으며, 운항데이터는 항로, 항해 정보, 대수속도, 대지속도, 바람과 같은 외력에 대한 정보 등이 있고, 기기데이터는 엔진출력, RPM, 연료 소모량, 기기들의 온도 및 압력 등이 있다. 본 연구에서, 우리는 선박에 미치는 외력의 영향을 Beaufort Scale (BFS)을 기 준으로 구분한 후에 PLS 회귀분석을 통한 예측 모델을 개발하였다.

주요용어: 선박 운항 효율, 보퍼트 풍력계급, PLS 회귀분석

이 논문은 2016 년 해양수산부 재원으로 한국해양과학기술진흥원의 지원을 받아 수행된 연구임(친환경선박 TCS 시스템 구축).

${ }^{1}$ 교신저자: (37673) 경북 포항시 남구 청암로 77 , 포항공과대학교 산업경영공학과.

E-mail: chjun@postech.ac.kr 